Original Article

\title{
SYNTHESIS AND CHARACTERIZATION IN VITRO ANTIMICROBIAL AND CYTOTOXICITY TESTING OF OXALIC ACID-DERIVED CADMIUM CHELATING AGENTS
}

\author{
DAISY SELASTEEN $\mathrm{F}^{*}$, ALFRED CECIL RAJ $\mathrm{S}^{\mathrm{a}}$, ALAGAPPA MOSES $\mathrm{A}^{\mathrm{b}}$
}

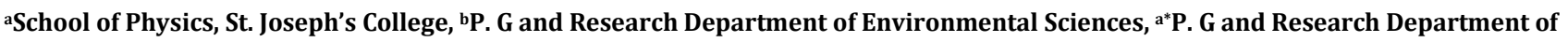
Physics, Bishop Heber College, Tiruchirappalli, Tamil Nadu, India

Email: fdaisyallen77@gmail.com

Received: 18 Mar 2018 Revised and Accepted: 06 Jun 2018

\begin{abstract}
Objective: The aim of this study is to investigate the growth, structure, spectral, solubility and biological activity of sodium cadmium oxalate dehydrate $(\mathrm{NaCdOx})$ and cadmium oxalate trihydrate (CdOx) crystals prepared by a single diffusion method in the silica gel medium.

Methods: The present crystals were grown using single diffusion methods and tested for XRD, UV absorption (190 to $1100 \mathrm{~mm}$ ) and solubility (distilled water at $20-29^{\circ} \mathrm{C}$ ) studies. The antimicrobial efficacy of the grown samples at various concentrations $(25,50,75$ and $100 \mu \mathrm{g} / \mathrm{ml}) \mathrm{was}$ studied against Streptococcus, (G+Ve), Pseudomonas aeruginosa (G-Ve) and Candida albicans (antifungal). The cytotoxicity evolution was carried out against human cervical cancer cell line (HeLa) using MTT assays.
\end{abstract}

Results: The existing single crystals were successfully grown by silica gel technique. The solubility of sodium cadmium oxalate dehydrate (NaCdOx) was moderately good in deionized warm water. The FTIR spectral studies confirmed the chelating bands of the present samples and UV spectra showed the better the optical conductivity of as-grown crystals. The complexes showed good antimicrobial activity against all tested microbial strains and they exhibited a decrease in cytotoxicity activity.

Conclusion: The gel method was suitable to grow metal complexes of legend crystals. The modification of structural properties of cadmium oxalate trihydrate ( $\mathrm{CdOx}$ ) by sodium doping was much improved the solubility, anticancer, antimicrobial activity and polarization by the high optical conductivity of sodium cadmium oxalate dehydrate ( $\mathrm{NaCdOx}$ ) compound. Hence sodium cadmium oxalate dehydrate (NaCdOx) might be a candidate for biomedical applications.

Keywords: $\mathrm{Na}_{4} \mathrm{Cd}_{2}\left(\mathrm{C}_{2} \mathrm{O}_{4}\right){ }_{4} .4 \mathrm{H}_{2} \mathrm{O}$ crystal growth, Single crystal XRD, FTIR, UV, Biological activity studies

(c) 2018 The Authors. Published by Innovare Academic Sciences Pvt Ltd. This is an open access article under the CC BY license (http://creativecommons.org/licenses/by/4.0/) DOI: http://dx.doi.org/10.22159/ijpps.2018v10i7.26034

\section{INTRODUCTION}

Cadmium is a widely, but sparsely distributed element found in the earth's crust at concentrations ranging from 0.1 to $1 \mathrm{ppm}$. The highest cadmium potential exposures occur in the cadmium-nickel battery, cadmium pigment, polyvinyl chloride compound and cadmium alloy manufacturing and refining industries. Cadmium ions are absorbed by most tissues of the body and become concentrated mainly in liver and kidney. Oxalic acid, a kind of organic acid, which has often played a major role in alleviating metal toxicity via a variation of the mobility and bioavailability of heavy metals $[1,2]$. It is a natural chemotherapy void of troubling side effects and is a usual element in human blood and must be accessible for the immune system to fight against the diseases of cancer, viral, bacterial and vascular conditions. It has a mean value of $288 \mathrm{mg}$ of anhydrous oxalic acid/ $100 \mathrm{ml}$ of blood. When it falls below an effective level the immune system can no longer protect the body from various diseases [3]. Oxalic acid induces to cure cancer in the human. Having cancer and are currently receiving radiation and have become infected with a virus, requires eating a diet to elevate the oxalic acid levels and stop blocking oxalic acid in the blood [4]. In the body, oxalic acid combines with divalent $\left(\mathrm{Cd}^{2+)}\right.$ metals to form crystals of the corresponding oxalates, which are then excreted in urine as minute crystals. Importantly, oxalate is often encountered as a bidentate, chelating ligand $\left(\mathrm{C}_{2} \mathrm{O}_{4}{ }^{2-}\right)$, for metal cations. The use of an oxalate to bind with a metal ( $\mathrm{as} \mathrm{Fe}, \mathrm{Na}, \mathrm{Cd}, \mathrm{Zn}$, and $\mathrm{Cu}$ ) in the body to form a chelate so that the metal loses its toxic effect or physiological activity. Mainly atoms like $\mathrm{C}$ and $\mathrm{O}$ function as ligand atoms in the form of $\mathrm{C}=0$ chemical group in a bidentate oxalate ligand bites the metal cation in two places at a time produces a strong chelated compound to extract divalent metals from kidney and lever. Chelation occurs through carboxylate oxygen and the adjacent hydroxyl group responding (i) a stable dodecahedral environment and (ii) bridging takes place through the coordinated carboxyl or the hydroxyl groups. Hence the chelating compounds are found to be potential candidates for the removal of heavy metals in the order of trisodium citrate>disodium oxalate>sodium sulfate has been reported [5]. The formation of a metal-oxalate complex, therefore, may provide a detoxification on metal bioavailability. Recently, an octahedral cadmium complex containing a tetradentate acyclic legend with antimicrobial potency has been reported [6]. In another report, Roy et al. Have been presented a synthesis of antibacterial/antifungal active cadmium complex of a macrocyclic ligand [7]. Recently, some new coordination cadmium, Nickel and Copper complexes have been reported with suitable antimicrobial activities [8]. Some cadmium complexes have also been shown biological properties in vitro [9]. To the best of our knowledge, we report the structural, optical and biological properties of cadmium mixed chelating compounds.

\section{MATERIALS AND METHODS}

The high-purity elements such as cadmium chloride (LOBA Chemie, $99.95 \%$ Assay), sodium chloride (LOBA Chemie, $99.95 \%$ Assay), oxalic acid (LOBA Chemie, $99.99 \%$ Assay), and sodium metasilicate (LOBA Chemie, $99.9 \%$ Assay) with AR grade were used as the starting materials in the single diffusion chemical reaction method at a temperature of $28^{\circ} \mathrm{C}$. ENRAF NONIUS CAD4 X-Ray diffractometer equipped with MoKo radiation was employed to estimate the unit cell parameters of the as-grown crystals. The various analyses were carried out at room temperature. The FTIR analysis was carried out using PERKIN ELMER FTIR spectrometer by $\mathrm{KBr}$ pellet technique for identifying the presence of functional groups and the coordination of disodium cadmium oxalate and Cadmium oxalate ( $\mathrm{CdOx})$. The spectrum was recorded within the range of $400 \mathrm{~cm}^{-1}$ to $4000 \mathrm{~cm}^{-1}$. The optical characterization of sodium cadmium oxalate dihydrate (NaCdOx) and cadmium oxalate trihydrate (CdOx) crystals were carried with the help of a LAMBDA 35 UV Visible spectrophotometer. The absorption spectrum was traced within the range 
of 190 to $1100 \mathrm{~mm}$. The antimicrobial activity assayed against Streptococcus, $(\mathrm{G}+\mathrm{Ve})$, Pseudomonas aeruginosa $(\mathrm{G}-\mathrm{Ve})$ and Candida albicans (antifungal) according to agar well diffusion method [10]. Nutrient agar (Merck, Germany) was used as solid media for preparing of nutrient plates while the Mueller Hinton broth was applied as liquid culture media in biological tests. Bacterial cultures such as Streptococcus, $(\mathrm{G}+\mathrm{Ve})$, Pseudomonas aeruginosa $(\mathrm{G}-\mathrm{Ve})$ and Candida albicans (antifungal) were obtained from Eumic analytical Lab and Research Institute, Tiruchirappalli, Tamil Nadu, South India. Bacterial strains were maintained on Nutrient agar slants (Himedia) at $4{ }^{\circ} \mathrm{C}$. Bacterial cultures were subcultured in liquid medium (Nutrient broth) at $37^{\circ} \mathrm{C}$ for $8 \mathrm{~h}$ and further used for the test $\left(10^{5}\right.$ $10^{6} \mathrm{CFU} / \mathrm{ml}$ ). These suspensions were prepared immediately before the test was carried out. The cytotoxicity of dicarboxylate based legends and its metal complexes were investigated on human cervical cancer cell line (HeLa) by means of MTT assays. The human cervical cancer cell line (HeLa) was obtained from National Centre for Cell Science (NCCS), Pune and grown in the Minimum Essential Medium containing 10\% fetal bovine serum (FBS). The cells were maintained at $37{ }^{\circ} \mathrm{C}, 5 \% \mathrm{CO}_{2}, 95 \%$ air and $100 \%$ relative humidity. IC50 is employed to stand for the cytotoxicity of the compounds against the cancer cell lines; the smaller the IC50 value in the same condition is the higher the cell growth inhibitory potency.

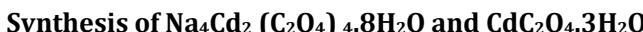

The growth of sodium cadmium oxalate dihydrate ( $\mathrm{NaCdOx}$ ) and cadmium oxalate trihydrate ( $\mathrm{CdOx}$ ) crystals were carried out in silica gel media by adopting the single-diffusion technique. The sodium cadmium oxalate dihydrate $(\mathrm{NaCdOx})$ was prepared by gradual addition of cadmium chloride $(2 \mathrm{mmol}$ in $10 \mathrm{ml}$ of water $)$ to a freshly prepared silica hydrogel [addition of sodium metasilicate solution (1.03 specific gravity) to oxalic acid $(2 \mathrm{ml}$ in $10 \mathrm{ml}$ of water)], maintaining the $\mathrm{pH}$ at 4.5 and then left for a few days at room temperature for crystallization of the complexes. When sodium metasilicate goes into a solution, mono silicic acid is expected to be produced [11] according to the following reaction (1).

\section{$2 \mathrm{Na}_{2} \mathrm{SiO}_{3}+6 \mathrm{H}_{2} \mathrm{O} \rightarrow 2 \mathrm{H}_{4} \mathrm{SiO}_{4}+4 \mathrm{NaOH}(1)$}

This sodium hydroxide is expected to react with oxalic acid, diffusing in a gel from the supernatant solution and forming sodium mixed cadmium oxalate crystals by the following reaction (2).

$4 \mathrm{NaOH}+4 \mathrm{H}_{2} \mathrm{C}_{2} \mathrm{O}_{4} \cdot \mathrm{H}_{2} \mathrm{O}+2 \mathrm{CdCl}_{2} \rightarrow \mathrm{Na}_{4}\left[\mathrm{Cd}_{2}\left(\mathrm{C}_{2} \mathrm{O}_{4}\right)_{4}\right] .8 \mathrm{H}_{2} \mathrm{O}+4 \mathrm{HCl}$. (2)

After passing one week, the $\left[\mathrm{Na}_{4}\left[\mathrm{Cd}_{2}\left(\mathrm{C}_{2} \mathrm{O}_{4}\right)_{4}\right.\right.$.]. $\left.8 \mathrm{H}_{2} \mathrm{O}\right]$ was obtained as suitable single crystals for $\mathrm{X}$-ray diffraction analysis. The preparation and growth of $\mathrm{CdC}_{2} \mathrm{O}_{4} \cdot 3 \mathrm{H}_{2} \mathrm{O}$ single crystals in the silica gel medium were done as similar to the method which has been reported [12] already.

\section{Particle size}

The structure of as-grown samples was solved by the direct method and refined by the full matrix least square technique employing the SHELXL program. The Particle size of the sodium cadmium oxalate dihydrate $(\mathrm{NaCdO} \mathrm{x})$ and cadmium oxalate trihydrate $(\mathrm{CdOx})$ were measured by $0.30 \times 0.25 \times 0.20 \mathrm{~mm} 3$ and $0.150 \times 0.100 \times 0.100 \mathrm{~mm}^{3}$ using single crystal X-ray diffraction analysis method.

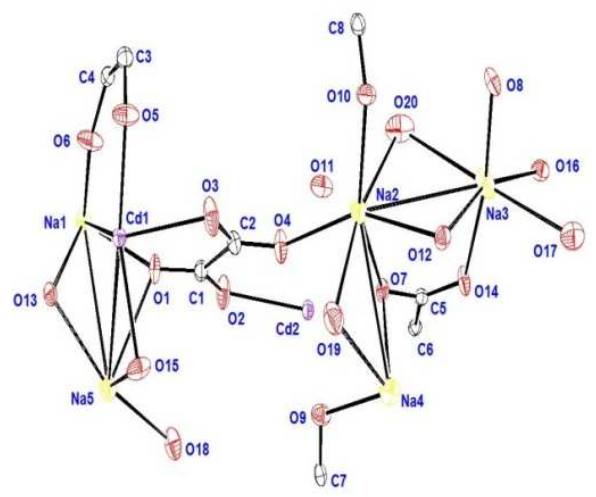

(A)

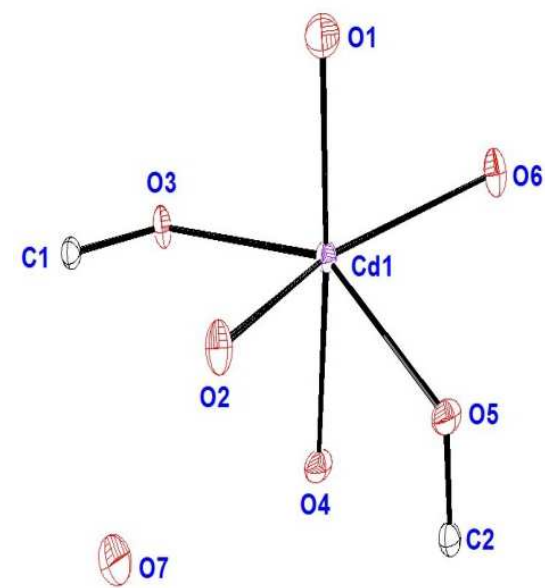

(B)

Fig. 1: The molecular arrangement and atom numbering scheme of, (A): sodium cadmium oxalate dihydrate ( $\mathrm{NaCdOx}$ );

(B): cadmium oxalate trihydrate (CdOx) crystals

\section{RESULTS AND DISCUSSION}

\section{Single crystal $\mathrm{x}$-ray diffraction analysis}

Single crystal X-ray diffraction analysis of the grown cadmium (II) crystals has been carried out to identify the cell parameters using an ENRAF NONIUS CAD 4 automatic X-ray diffractometer. The title complex $\left[\mathrm{Na}_{4} \mathrm{Cd}_{2}\left(\mathrm{C}_{2} \mathrm{O}_{4}\right)_{4.4} 4 \mathrm{H}_{2} \mathrm{O}\right]_{\mathrm{n}}$, the calculated lattice parameters are $\mathrm{a}=12.83 \mathrm{~A}^{\circ}, \mathrm{b}=11.43 \mathrm{~A}^{\mathrm{o}}, \mathrm{c}=14.11 \mathrm{~A}^{\circ}, \quad \beta=113.02^{\circ}$ and it crystallizes in the monoclinic form with $\mathrm{P}_{21 / \mathrm{n}}$ space group through cadmium (II) atom lying on a centre of symmetry. The calculated structural parameters of the sodium cadmium oxalate dihydrate (NaCdOx) and cadmium oxalate trihydrate (CdOx) crystals are shown in table 1. Each cadmium (II) atom of sodium cadmium oxalate dihydrate $(\mathrm{NaCdOx})$ is coordinated by four oxygen atoms of two bidentate oxalate dianions with a distorted square-planar geometry as shown in fig. 1 (A). The other two oxygen atoms of each oxalate group coordinate to the sodium atom which connects the $\left[\mathrm{Cd}(\mathrm{ox})_{2}\right]^{-2}$ units. In the structure of sodium, cadmium oxalate dehydrate $(\mathrm{NaCdOx})$ complex, the repeat unit has two oxalate groups, one cadmium (II) atom, two sodium atoms and four water molecules. The oxalate legend has an inversion center at the midpoint of the C-C bond. The improved biological activities of the as-grown samples are mainly done by the occurrence of the $\mathrm{C}=0$, $\Pi$ bonds and intermolecular hydrogen bonds $\mathrm{O}-\mathrm{H}----\mathrm{O}$ (hydroxyl group) in the crystal structure. In addition to that, the conductivity and the polarity of the inorganic centro symmetric metal oxalate salts are due to the presence of asymmetric $\mathrm{O}-\mathrm{H}$ bond, polar $\mathrm{C}=\mathrm{O} \Pi$ bond, and $\mathrm{C}-\mathrm{O}$ asymmetric stretching bonds, which contribute to the strong delocalization of $\pi$ electron conjugation system in the bimetallic-oxalate matrix [13]. Furthermore, the overlap of $\Pi$ orbitals can generate charge carrier distribution in a molecule leads to higher order optical and polarization efficiency of the asgrown samples, suitable for biological activity of the as-grown metal complexes of ligand crystals. The bond length of the $\mathrm{C}-\mathrm{O}$ bond, $\mathrm{C}=\mathrm{O}, \Pi$ bonds and $\mathrm{O}-\mathrm{H}----\mathrm{O}$ bonds for sodium cadmium oxalate dihydrate $(\mathrm{NaCdOx})$ is larger than the cadmium oxalate trihydrate (CdOx) (table 2, table 3 ) revealed the stability and strong chelating activity of the sodium cadmium oxalate dihydrate (NaCdOx) than the cadmium oxalate trihydrate (CdOx) metal complexes. In the pure cadmium oxalate trihydrate ( $\mathrm{CdOx}$ ) structure in fig. 2 (B) shows the calculated lattice parameters are a $=5.99 \AA, b=6.65 \AA, c=8.40 \AA, \gamma=81.04^{\circ}$ and the crystal belongs to the triclinic crystal system with the $\mathrm{P}_{-1}$ space group through cadmium atom lying on a center of symmetry is coordinated by eight oxygen atoms in which four from oxalate units and four from water molecules. These results are well agreed with the previously reported results [14]. 
Table 1: Crystal data of the studied compounds

\begin{tabular}{|c|c|c|}
\hline Lattice parameters & Sodium cadmium oxalate dihydrate (NaCdOx) & Cadmium oxalate trihydrate (CdOx) \\
\hline Empirical formula & $(\mathrm{C} 4 \mathrm{H} 4 \mathrm{Cd} \mathrm{Na} 2 \mathrm{O} 10)_{\mathrm{n}}$ & $(\mathrm{C} 2 \mathrm{H} 6 \mathrm{Cd} \mathrm{07})_{\mathrm{n}}$ \\
\hline Formula weight & 812.508 & 254.47 \\
\hline Crystal system & Monoclinic & Triclinic \\
\hline Space group & $\mathrm{P}_{21 / \mathrm{n}}$ & $\mathrm{P}_{-1}$ \\
\hline \multirow[t]{3}{*}{ Unit cell dimensions } & $a=12.8566(6) \AA \AA: \alpha=90^{\circ}$ & $\mathrm{a}=5.9944(2) \AA: \alpha=74.63^{\circ}$ \\
\hline & $b=11.4338(5) \AA: \beta=113.07^{\circ}$ & $b=6.6531(2) \AA . . \beta=4.28^{\circ}$. \\
\hline & $c=14.1144(6) \mathrm{A}: \gamma=90^{\circ}$ & $c=8.4731(3) \AA: \gamma=81.04^{\circ}$ \\
\hline
\end{tabular}

Table 2: Selected carbon-carbon (C-C) and carbon-oxygen (C-O) bond lengths of as-grown crystals

\begin{tabular}{|c|c|c|c|}
\hline \multicolumn{2}{|c|}{ Sodium cadmium oxalate dihydrate $(\mathrm{NaCdO})$ crystal $(\mathrm{A})^{\mathrm{a}}$} & \multicolumn{2}{|c|}{ Cadmium oxalate trihydrate (CdOx) crystal (A) a } \\
\hline $\mathrm{C}(1)-0(1)$ & $1.246(3) \pm 0.04$ & $\mathrm{C}(1)-\mathrm{C}(1)$ & $1.546(2) \pm 0.02$ \\
\hline $\mathrm{C}(1)-0(2)$ & $1.248(3) \pm 0.03$ & $\mathrm{C}(1)-0(3)$ & $1.2589(15) \pm 0.04$ \\
\hline $\mathrm{C}(1)-\mathrm{C}(2)$ & $1.559(3) \pm 0.02$ & $\mathrm{C}(1)-0(6)$ & $1.2407(17) \pm 0.03$ \\
\hline $\mathrm{C}(2)-0(4)$ & $1.240(3) \pm 0.02$ & $\mathrm{C}(2)-0(5)$ & $1.2449(17) \pm 0.02$ \\
\hline
\end{tabular}

${ }^{a}$ mean \pm SD

Table 3: Selected hydrogen bonds and bond angles of the studied crystals

\begin{tabular}{|c|c|c|c|c|c|c|}
\hline $\begin{array}{l}\text { S. } \\
\text { No. }\end{array}$ & Compound & $\begin{array}{l}\text { Hydrogen bond } \\
\text { formation [O-H. 0] }\end{array}$ & $\begin{array}{l}\text { Bond length }[\mathrm{O}-\mathrm{H}] \\
\text { a (A) * }\end{array}$ & $\begin{array}{l}\text { Bond length [H. O] } \\
\text { b (A) * }\end{array}$ & $\begin{array}{l}\text { Bond length [0. 0] } \\
\text { c (A) * }\end{array}$ & $\begin{array}{l}\text { Bond angle } \\
(\mathrm{OHO})^{d}(\mathrm{deg}) *\end{array}$ \\
\hline 1 & $\begin{array}{l}\text { sodium cadmium oxalate } \\
\text { dihydrate }(\mathrm{NaCdOx})\end{array}$ & $\begin{array}{l}\mathrm{O}(18)-\mathrm{H}(18 \mathrm{~A}) . \mathrm{O}(3) \\
\# 4\end{array}$ & $0.837(17) \pm 0.02$ & $1.974(18) \pm 0.3$ & $2.805(2) \pm 0.4$ & $172(3) \pm 0.1$ \\
\hline 2 & & $\begin{array}{l}\mathrm{O}(17)-\mathrm{H}(17 \mathrm{~B}) \cdot \mathrm{O} \\
(5) \# 3\end{array}$ & $0.830(17) \pm 0.01$ & $1.867(17) \pm 0.4$ & $2.692(2) \pm 0.3$ & $173(3) \pm 0.1$ \\
\hline 1 & $\begin{array}{l}\text { cadmium oxalate } \\
\text { trihydrate (CdOx) }\end{array}$ & $\mathrm{O}(1)-\mathrm{H}(1 \mathrm{~B}) . \mathrm{O}(7) \# 6$ & $0.87(3) \pm 00.02$ & $1.89(3) \pm 0.5$ & $2.726(2) \pm 0.2$ & $160(3) \pm 0.1$ \\
\hline 2 & & $\mathrm{O}(7)-\mathrm{H}(7 \mathrm{~A}) \cdot \mathrm{O}(4)$ & $0.81(3) \pm 0.03$ & $2.11(3) \pm 0.2$ & $2.8974(19) \pm 0.1$ & $163(3) \pm 0.1$ \\
\hline
\end{tabular}

aSymmetric stretching mode of oxygen-hydrogen atoms, basymmetric stretching mode of hydrogen-oxygen atoms, casymmetric stretching mode of oxygen-oxygen atoms, dAngle between $L O H O$ water molecules. ${ }^{*}$ mean \pm SD

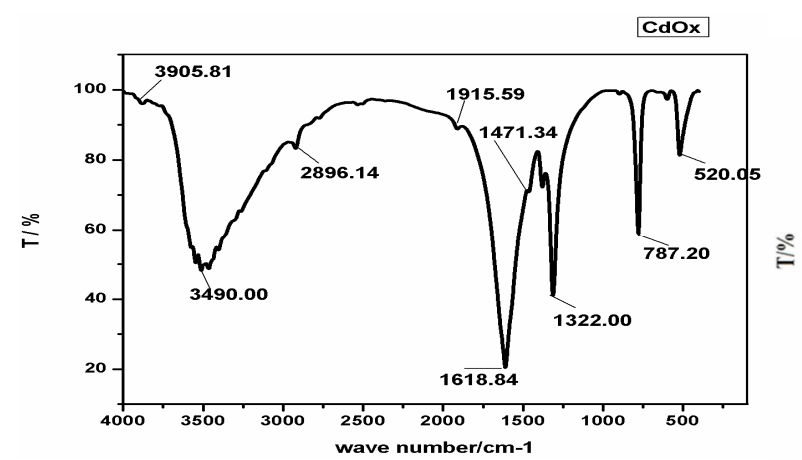

(A)

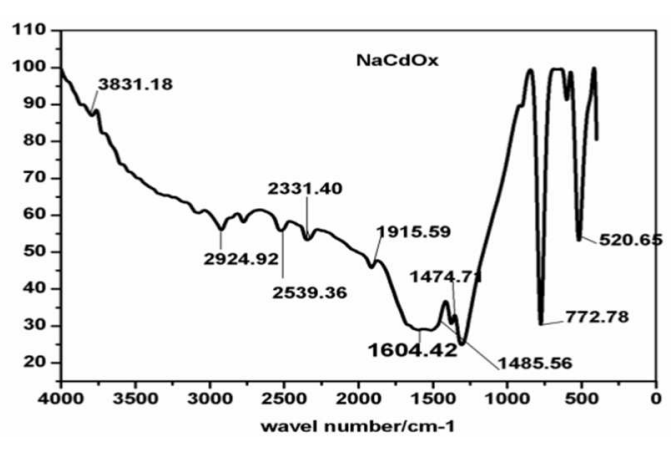

(B)

Fig. 3: FTIR spectrum of, (A): cadmium oxalate trihydrate (CdOx) crystal; (B): sodium cadmium oxalate dihydrate (NaCdOx) crystal

\section{FTIR spectral studies}

FTIR absorption spectra of the grown sodium doped cadmium oxalate and cadmium oxalate single crystals were recorded from $400 \mathrm{~cm}^{-1}$ to $4000 \mathrm{~cm}^{-1}$ (fig. 3). The broad envelope extending from $2500 \mathrm{~cm}^{-1}$ to 3905 $\mathrm{cm}^{-1}$ are assigned to be due to the symmetric and asymmetric stretching modes of the chelating water molecules. The broadband at $3490 \mathrm{~cm}^{-1}$ in the spectra of the cadmium oxalate trihydrate ( $\mathrm{CdOx}$ ) metal complexes is assigned to the $v(\mathrm{OH})$ frequency of the coordinated $\mathrm{H}_{2} \mathrm{O}$. This shift further confirms the participation of the oxygen from water molecules leading to the formation of the C-O-M bond. In addition to that, the metal complexes show a broadband at $3400 \mathrm{~cm}^{-1}$ and a new band at $786 \mathrm{~cm}^{-1}$ that may be assigned to the stretching vibration and out of plane bending vibration of water molecules. The strong band observed at $1604.42 \mathrm{~cm}^{-1}$ to $1618.84 \mathrm{~cm}^{-1}$ in the spectra of the sodium cadmium oxalate dihydrate (NaCdOx) and cadmium oxalate trihydrate ( $\mathrm{CdOx}$ ) ligands is a characteristic of the asymmetric stretching vibrations of $\mathrm{C}-\mathrm{O}$ groups of the $\mathrm{C}_{2} \mathrm{O}_{4}^{2-}$ ions together with the bending mode of water reveals the chelating agents of the as-grown crystals. The asymmetric stretching, vibration bands of carboxylate groups emerging at1608. $61 \mathrm{~cm}^{-1}(\mathrm{C}=0)$ and $1607.12 \mathrm{~cm}^{-1}$ suggests the presence of two coordination modes [15] and also a band at $1471.33 \mathrm{~cm}^{-1}(\mathrm{C}-\mathrm{H})$ and $1474.73 \mathrm{~cm}^{-1}$ are assigned to symmetric stretching of a major bioactive COO-group of the complex of sodium cadmium oxalate dihydrate $(\mathrm{NaCdOx})$ and cadmium oxalate trihydrate (CdOx) crystals. This shift can further be explained by the donation of electrons from the oxygen to the empty d-orbitals of the metal ions. The separation $\Delta v$, between $v_{a s y}$ and $v_{s y}$, sodium cadmium oxalate dihydrate ( $\mathrm{NaCdOx}$ ), and cadmium oxalate trihydrate (CdOx) crystals are $147.50 \mathrm{~cm}^{-1}$ and $133.71 \mathrm{~cm}^{-1}$ which indicate the chocolate bidentate coordination of the carboxylate group to the central metal cadmium ion as is evident from single crystal x-ray diffraction studies. This shift of carboxyl stretching, vibration strongly supports its coordination to Cd ion [16]. The FTIR bands of sodium cadmium oxalate dihydrate ( $\mathrm{NaCdOx})$ and cadmium oxalate trihydrate $(\mathrm{CdOx})$ at 1322.00 
$\mathrm{cm}^{-1}$ and $1307.86 \mathrm{~cm}^{-1}(\mathrm{O}-\mathrm{C}=0)$ corresponds to the $\mathrm{C}-\mathrm{OH}$ bending and the band at $786.69 \mathrm{~cm}^{-1}$ and $777.41 \mathrm{~cm}^{-1}(\mathrm{C}-\mathrm{C})$ corresponds to scissoring vibrations in the carboxyl groups and furthermore, the band at 520.65 $\mathrm{cm}^{-1}$ corresponds to M-O bond $[17,18]$.

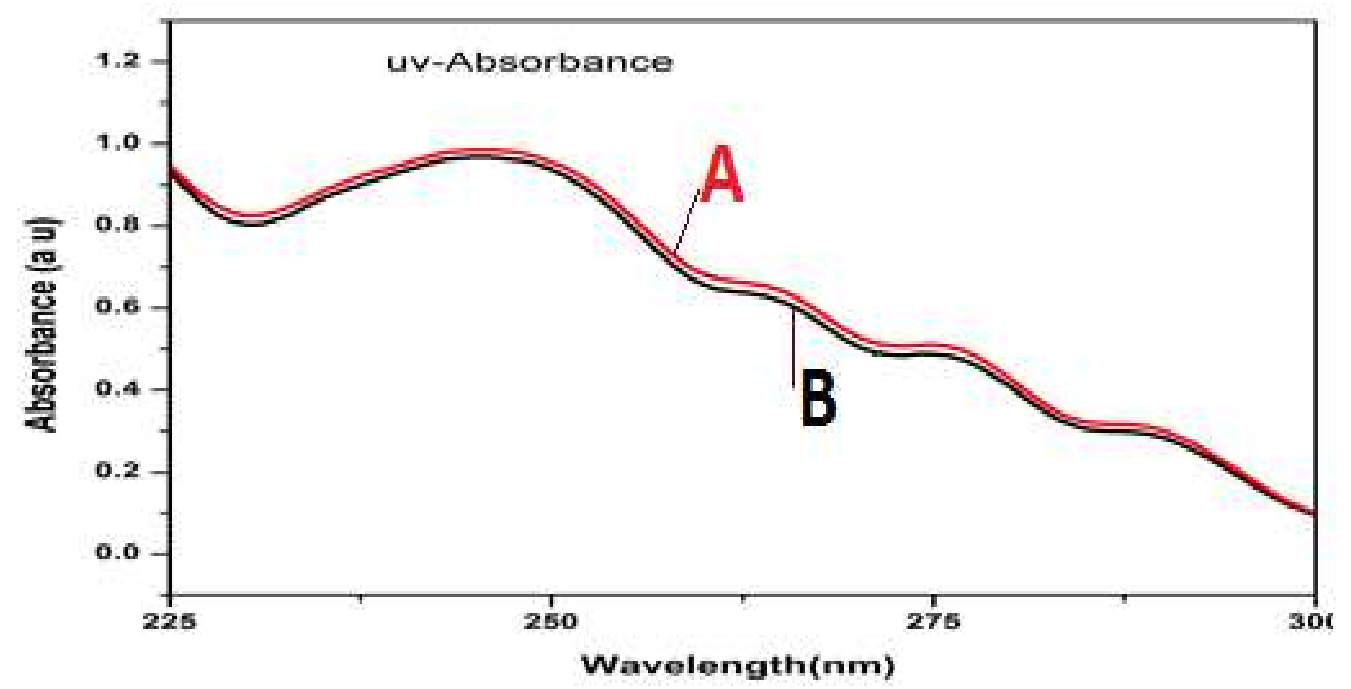

Fig. 5: Absorption spectra of, (A): sodium cadmium oxalate dihydrate (NaCdOx); (B): cadmium oxalate trihydrate (CdOx) crystals

\section{UV-absorption spectral analysis}

The UV-Vis Absorption spectra of sodium cadmium oxalate dihydrate ( $\mathrm{NaCdOx}$ ) and cadmium oxalate trihydrate (CdOx) (fig. 5) which shows two bands at $245.94 \mathrm{~nm}$ and $242.34 \mathrm{~nm}$. The first band can be attributed to $\pi-\pi$ transition within the oxalate unit, while the second band would be due to $n-\pi$ transition within $-\mathrm{C}=\mathrm{H}$ group. The optical conductivity in the inorganic centro symmetric metal oxalate salts is due to the presence of asymmetric $\mathrm{O}-\mathrm{H}$ bond, polar $\mathrm{C}=\mathrm{O} \Pi$ bond, and $\mathrm{Cd}-\mathrm{O}-\mathrm{Na}$ asymmetric stretching bonds, which donate to the strong $\Pi$ electron charge transfer system in the bimetallic-oxalate matrix [19]. Upon coordination complex, $n-\pi$ transition of ligand shifts to a longer wavelength. This indicates the coordination of ligand to metal. The cadmium ion has an oxidation number equal to $(+2)$ and coordination number equal to ' 8 ' due to the coordination of oxalate anion to a metal as a bidentate chelate. The cadmium ion has ground state 2D and the electronic spectra of the sodium cadmium oxalate dihydrate ( $\mathrm{NaCdOx}$ ) and cadmium oxalate trihydrate (CdOx) complexes exhibited maximum at $245.94 \mathrm{~nm}$ (absorbance was 1.00 a. u) and 242.34 $\mathrm{nm}$ (absorbance was $0.9303 \mathrm{a} . \mathrm{u}$ ) are attributed $(\pi-\pi *)$ transition which means ultraviolet region and charge transfer from ligand to metal, an electron moves to ligand-to-metal charge transfer (LMCT) [20]. The sharp absorption peaks observed in both the spectra of the UV region is done by the splitting of transition of energy levels of metal ions in the ' $d$ 'orbital from the highest occupied orbital to the lowest unoccupied ' $d$ ' orbital of $\mathrm{Cd} 2+$ when UV light is absorbed. Hence the amount of splitting of the energy levels depends on the ligand around a cadmium metal ion, increases the stability, optical conductivity and polarization of the sodium cadmium oxalate dihydrate ( $\mathrm{NaCdOx}$ ) and cadmium oxalate trihydrate (CdOx) complexes formed in view of the fact that the difference between the energy levels of the ' $\mathrm{d}$ ' orbital increases. As a result, these metal complexes of ligand exhibit two excitation bands from $240 \mathrm{~nm}$ to $300 \mathrm{~nm}$ of sharp absorption peaks at near UV regions.

\section{Antimicrobial screening studies}

\section{Kirby-bauer agar well diffusion assay}

The nutrient agar medium was prepared and sterilized by autoclaving at $121^{\circ} \mathrm{C}$ and $15 \mathrm{lbs}$. Pressure for $15 \mathrm{~min}$, then aseptically poured the medium into the sterile Petri plates and allowed to solidify. Then the Bacterial broth culture was swabbed on each Petri plates using sterile buds. Finally, the wells were made by the good cutter. The organic solvent extracts of leaves were added to each well aseptically.

This procedure was repeated for each Petri plate and they were incubated at $37^{\circ} \mathrm{C}$ for $24 \mathrm{~h}$. After incubation, the plates were observed in the zone of inhibition. The antibacterial and antifungal activity of metal complexes of the ligand of the asgrown title compound sodium cadmium oxalate dihydrate (NaCdOx) and cadmium oxalate trihydrate (CdOx) (fig. 6, fig. 7) are tested by the disc diffusion technique (table 4). Results were compared with standard drug gentamycin at the same concentration. The increased bond length of the structureactivity relationships between $\mathrm{O}-\mathrm{Na}-\mathrm{O}, \mathrm{O}-\mathrm{Cd}-\mathrm{O}$, and $\mathrm{O}-\mathrm{H}-\mathrm{O}$ in sodium cadmium oxalate dihydrate $(\mathrm{NaCdOx})$ is higher than the cadmium oxalate trihydrate ( $\mathrm{CdOx}$ ), showed that the biological properties of the complex enhance the antimicrobial activity rather than the mononuclear complex [21,22] is explained by the Overtone's concept and Tweedy's chelation theory [23]. According to Overtone's concept of cell permeability, the lipid membrane that surrounds the cell favors the passage of only lipid soluble materials since the lipid solubility is an important factor that controls the antimicrobial activity. The increasing lipid solubility character of the metal chelate favors its permeation through the lipid layer of the microorganism which probably leads to the breakdown of permeability barrier of cell process. During this process, an increase in the lipophilic nature of the central metal (II) ions which favor its permeation more efficiently through the lipid layer of the microorganisms, thus making the chelate compound more antimicrobial activity [24]. Coordination complex of antimicrobial active $\mathrm{C}=\mathrm{O}$ part with metal (II) ions reduces the polarity of cadmium (II) ions significantly because of partial sharing of its positive charge with donor groups and delocalization of p-electrons over the whole chelate resulting in high lipid solubility [25]. An increase in the concentration of test sample gives rise to more efficient effect against studied microorganisms. It has also been observed that concentration plays a vital role in increasing the degree of inhibition so that when the concentration is increased, the activity is also enhanced. The quantitative assays gave MIC values in the range $25 \mu \mathrm{g} / \mathrm{ml}-100 \mu \mathrm{g} / \mathrm{ml}$ is confirmed that the results are superior to the previously published values [26]. 


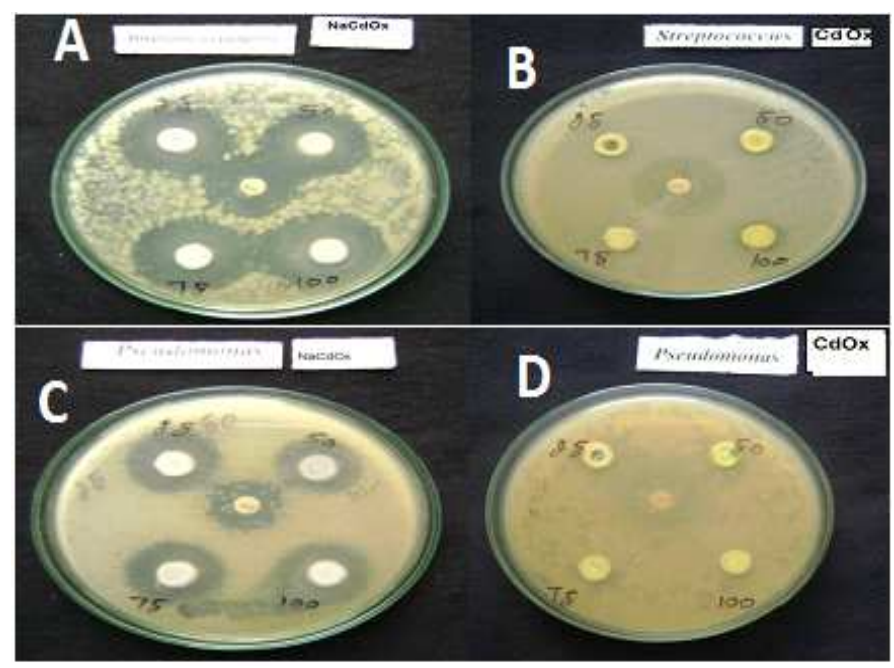

Fig. 6: Antibacterial activity of, (A): sodium cadmium oxalate dihydrate (NaCdOx) against Streptococcus; (B): cadmium oxalate trihydrate (CdOx) against Streptococcus; (C): sodium cadmium oxalate dihydrate (NaCdOx) against Pseudomonas; (D): cadmium oxalate trihydrate (CdOx) against Pseudomonas

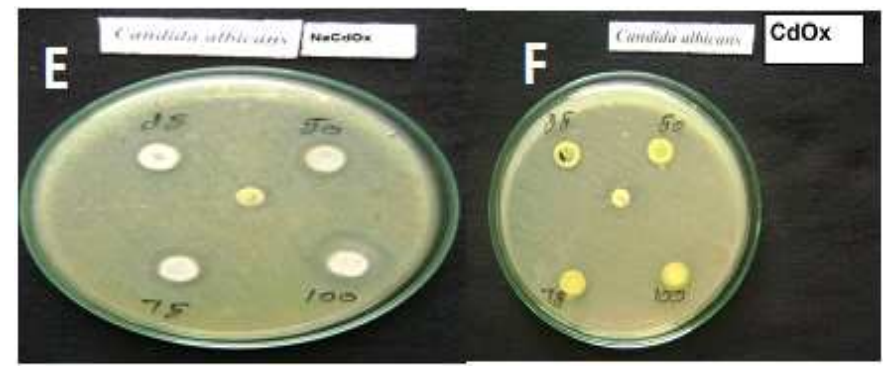

Fig. 7: Antifungal activity of, (E): sodium cadmium oxalate dihydrate (NaCdOx) against Candida albicans; (F): cadmium oxalate trihydrate (CdOx) against Candida albicans

Table 4: Antimicrobial activity of Cd (II) complexes

\begin{tabular}{|c|c|c|c|c|c|c|}
\hline \multirow[t]{3}{*}{ Compound } & \multirow[t]{3}{*}{ Organism } & \multirow{2}{*}{\multicolumn{4}{|c|}{$\begin{array}{l}\text { Minimum Zone of Inhibition }(\mathrm{mm}){ }^{*} \\
\text { Concentration }(\mu \mathrm{g} / \mathrm{ml})\end{array}$}} & \multirow[t]{3}{*}{ Control } \\
\hline & & & & & & \\
\hline & & 25 & 50 & 75 & 100 & \\
\hline sodium cadmium oxalate dihydrate ( $\mathrm{NaCdOx})$ & Streptococcus & $26 \pm 0.2$ & $28 \pm 0.3$ & $30 \pm 0.3$ & $35 \pm 0.4$ & 22 \\
\hline cadmium oxalate dihydrate ( $\mathrm{CdOx})$ & Streptococcus & $12 \pm 0.4$ & $14 \pm 0.2$ & $16 \pm 0.4$ & $19 \pm 0.3$ & 30 \\
\hline sodium cadmium oxalate dihydrate $(\mathrm{NaCdOx})$ & Pseudomonas aeruginosa & $22 \pm 0.4$ & $24 \pm 0.3$ & $26 \pm 0.2$ & $30 \pm 0.4$ & 18 \\
\hline cadmium oxalate dihydrate ( $\mathrm{CdOx})$ & Pseudomonas aeruginosa & $12 \pm 0.3$ & $10 \pm 0.4$ & $12 \pm 0.3$ & $14 \pm 0.3$ & 16 \\
\hline sodium cadmium oxalate dihydrate ( $\mathrm{NaCdOx}$ ) & Candida albicans & $16 \pm 0.2$ & $19 \pm 0.4$ & $21 \pm 0.4$ & $24 \pm 0.2$ & 14 \\
\hline cadmium oxalate dihydrate (CdOx) & Candida albicans & $14 \pm 0.3$ & $10 \pm 0.2$ & $12 \pm 0.2$ & $16 \pm 0.2$ & 18 \\
\hline
\end{tabular}

$*$ mean \pm SD

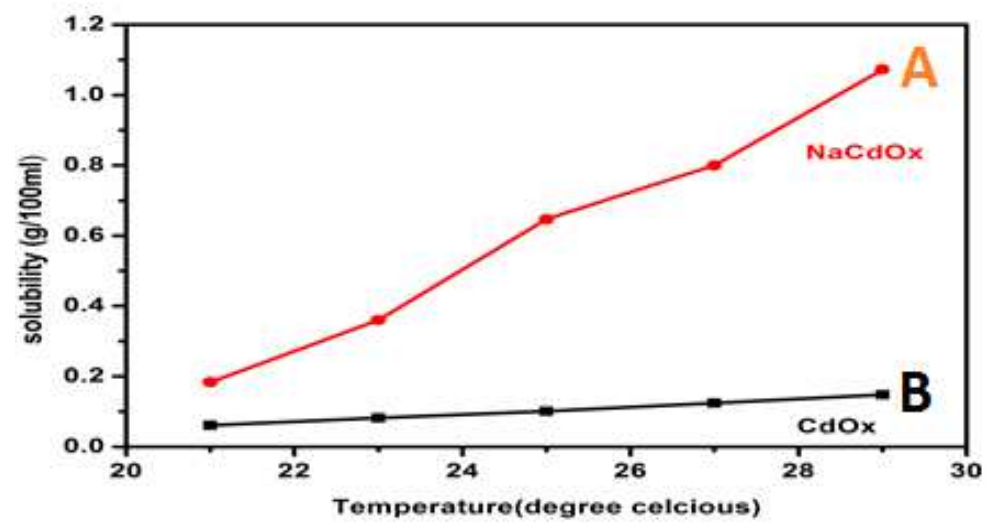

Fig. 9: Solubility curve of, (A): sodium cadmium oxalate dihydrate (NaCdOx); (B): cadmium oxalate trihydrate (CdOx) 


\section{Solubility study}

Solubility is one of the factors for better biological activities [27] of the as-grown samples was proved by solubility test using deionized warm water as a solvent. The solubility of pure and sodium doped cadmium oxalate was determined in the temperature range of $20^{\circ} \mathrm{C}$ to $29{ }^{\circ} \mathrm{C}$. Solubility studies were carried out in a constant temperature bath (CTB) with the cryostat facility with an accuracy of $+0.01 \mathrm{~K}$. The solution was stirred continuously for half an hour to achieve the stabilization. After attaining the saturation, the equilibrium concentration of the solute was analyzed gravimetrically. The same process was repeated and the solubility curves are observed to $0.05 \mathrm{~g} / 100 \mathrm{ml}$ and $1.5 \mathrm{~g} / 100 \mathrm{ml}$ for sodium cadmium oxalate dihydrate $(\mathrm{NaCdOx})$ and cadmium oxalate trihydrate $(\mathrm{CdOx})$ respectively, for different temperatures of the sodium cadmium oxalate dihydrate ( $\mathrm{NaCdOx}$ ) and cadmium oxalate trihydrate ( $\mathrm{CdOx}$ ) (fig. 9). It is observed from the curve that the solubility is found to increase with an increase in temperature for sodium cadmium oxalate dihydrate $(\mathrm{NaCdOx})$ than cadmium oxalate trihydrate ( $\mathrm{CdOx}$ ) was due to the hydrogen bonding between sodium cadmium oxalate dihydrate $(\mathrm{NaCdO})$ and the soluble nature of sodium oxalate in water. This result showed the sustained activity of the as-grown sodium cadmium oxalate dihydrate ( $\mathrm{NaCdOx}$ ) sample in its chelate form and the improved solubility demands the sodium cadmium oxalate dihydrate $(\mathrm{NaCdO})$ crystal for further pharmaceutical research and applications.

\section{Cytotoxicity studies}

The cytotoxicity of sodium cadmium oxalate dihydrate ( $\mathrm{NaCdOx}$ ) and cadmium oxalate trihydrate ( $\mathrm{CdOx}$ ) were investigated on human cervical cancer cell line (HeLa) by using the method of MTT assays. The cytotoxicity of the present compounds against the cancer cell lines was determined by IC50 values, the smaller the IC50 value in the same condition is the higher the cell growth inhibitory potency. When the warm water is used as the control without test sample, it does not exhibit any cytotoxic activity against all cancer cell lines. The IC50 values were calculated and are listed (table 5) after $48 \mathrm{~h}$ of incubation with compounds. The cytotoxicity activity of sodium cadmium oxalate dihydrate (NaCdOx) (fig. 11) metal complex against human cervical cancer cell line (HeLa) showed higher cytotoxicity than the cadmium oxalate trihydrate (CdOx) (fig. 12) is mainly due to its solubility and the less number of $\mathrm{C}=0$ chelating bonds compared to sodium cadmium oxalate dehydrate ( $\mathrm{NaCdOx}$ ) complex. These results revealed that the polymeric structural complication of sodium oxalate units with Cadmium (II) ions are significantly reducing the polarity of the metal ions into semi polarity and enhanced the lipophilic character of the central cadmium atom.
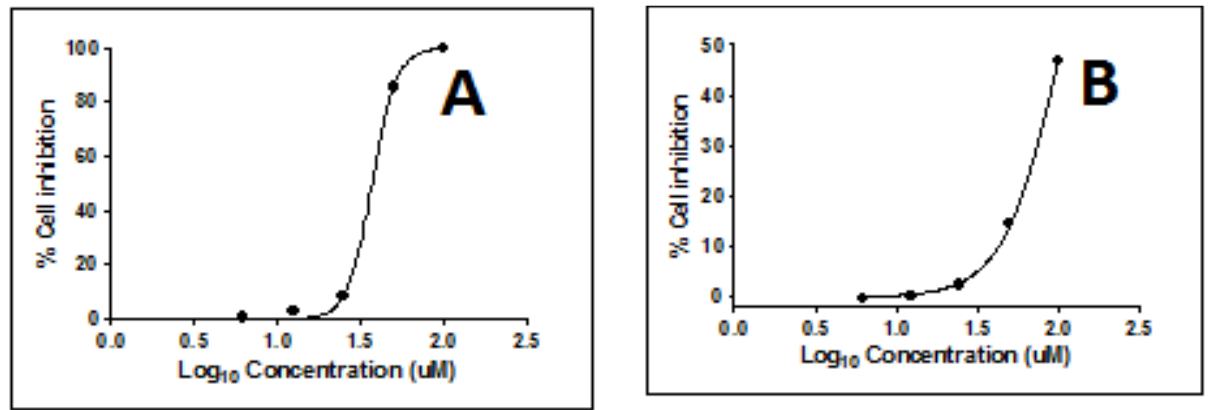

Fig. 11: Cytotoxicity of, (A): sodium cadmium oxalate dihydrate (NaCdOx); (B): cadmium oxalate dihydrate (CdOx)

Table 4: Calculated cytotoxicity values of sodium cadmium oxalate dihydrate (NaCdOx) and cadmium oxalate trihydrate (CdOx) towards human cervical (HeLa) cancer cell line

\begin{tabular}{lll}
\hline S. No. & Compound & IC50 ( $\boldsymbol{\mu M})$ \\
\hline 1 & cadmium oxalate trihydrate $(\mathrm{CdOx})$ & 105.4 \\
2 & sodium cadmium oxalate dihydrate $(\mathrm{NaCdOx})$ & 37.07 \\
\hline
\end{tabular}

${ }^{*} \mathrm{IC}_{50}$ : values indicate the effective concentration of a compound required to achieve $50 \%$ growth inhibition in $\mu \mathrm{g} / \mathrm{ml}$.

This kind of coordination complex may facilitate faster diffusion through biological membranes and also disturb the respiration process of the cells and thus restrict further growth of the organisms [28-30]. These factors are used to enhance the cytotoxic properties of sodium mixed cadmium complex by catalyzing cytotoxicity reactions [31].

\section{CONCLUSION}

The single crystals of cadmium oxalate trihydrate ( $\mathrm{CdOx}$ ) and sodium cadmium oxalate dihydrate $(\mathrm{NaCdOx})$ were grown by silica gel medium and the results of the structural analysis were indicated that by adding sodium, the triclinic structure of cadmium oxalate trihydrate (CdOx) transformed to the monoclinic structure was confirmed by single crystal x-ray diffraction (SXRD) diffraction studies. FT-IR band assignments have confirmed the presence of chelating agent groups of water of crystallization, metal-oxygen bonded groups and the oxalate phase transformation of as-grown cadmium (II) metal complexes of ligand crystals. The maximum absorbance in the UV spectrum revealed the superior optical conductivity was done by the polar $\mathrm{C}=0$, the $\Pi$ bond of the metal complexes of ligand crystals. The sodium cadmium oxalate dihydrate (NaCdOx) complex showed moderate solubility than the cadmium oxalate trihydrate (CdOx) complex owing to the presence of water- soluble disodium oxalate in its structure. Antibacterial activities of sodium cadmium oxalate dihydrate ( $\mathrm{NaCdOx})$ and cadmium oxalate trihydrate (CdOx) complexes were tested against different bacterial strains. The complexes showed good activity against all tested microbial strains. But the antibacterial activity of sodium cadmium oxalate dihydrate ( $\mathrm{NaCdOx}$ ) complex, against Pseudomonas aeruginosa, Streptococcus showed high was attributable to the remarkable properties of its solubility, optical conductivity, semi polarity and cell permeability mechanisms than the cadmium oxalate trihydrate (CdOx). The anticancer activity of the present cadmium (II) complexes was analyzed against on the human cervical cancer cell line (HeLa). This study revealed that the sodium cadmium oxalate dihydrate $(\mathrm{NaCdO} x)$ retained its activity against human cervical cancer cell line (HeLa) with the improved solubility. It demanded that enhanced optical conductivity properties of the asgrown sodium cadmium oxalate dihydrate ( $\mathrm{NaCdOx}$ ) single crystals are favourable for biomedical applications.

\section{ACKNOWLEDGEMENT}

The authors are also thankful to University Grants Commission, Grant no. F. NO: MRP-5808/15 (SERO/UGC) for providing financial support under Minor Research Project (MRP) scheme. We extend 
our heartfelt thanks to the Director, Central Electro Chemical Research Institute (CECRI), Karaikudi for UV studies, Dr, Athirajan, KMC college of Pharmaceutical Sciences, Coimbatore, Tamilnadu, for Anticancer activity studies, Dr. Senthil, Eumic research laboratory, SMS Hospital, Tiruchirappalli for Antimicrobial screening studies and also Dr. Sudha Devi, Sophisticated Analytical Instrument Facilities (SAIF), IIT-Chennai, for single crystal XRD analysis.

\section{AUTHORS CONTRIBUTIONS}

D. S. Performed the study, experimental synthesis, and the computational analysis. All authors equally contributed in writing the manuscript and approved the final description.

\section{CONFLICT OF INTERESTS}

We declare that we have no conflict of interest

\section{REFERENCES}

1. Brown GE, Foster AL, Ostergren JD. Mineral surfaces and bioavailability of heavy metals: a molecular-scale perspective. Proc Natl Acad Sci 1999;96:3388-95.

2. Chojnacka K, Chojnacki A, Gorecka H, Gorecki H. Bioavailability of heavy metals from polluted soils to plants. Sci Total Environ 2005;337:175-82.

3. Hodgkin Son. A Oxalic acid in biology and medicine. Febs Lett 1977;101:1-326.

4. Jennifer Prescott. Oxalic acid-the cure for cancer. Ezines Articles India: Ezines Publishers; 2008.

5. Atheer AM, Abdulqader MA, Mohammed Mosa Jafaar. Studying of transition metal complexes containing oxalate ion with antibacterial activity. Int J Sci Eng Res 2015;6:855-67.

6. Al-Jibouri MNA. Template synthesis of metal complexes from domino pyridine and dihydroquinoxalin-2, 3-dione. Eur Chem Bull 2014;3:384-9.

7. Tapaha G Roy, Saroj KS Hazari, Dong I Kim. Synthesis, electrolytic behavior and antimicrobial activities. Cadmium complexes of isomers of 3,10-C-meso-3,5,7,7,10,12,14,14octamethyl-1,4,8,11-tetraazacyclotetradecane. J Coord Chem 2007;60:1567-78.

8. Montazerozohori M, Yadegari S, Naghiha A. Synthesis, characterization, electrochemical behavior and antibacterial/ antifungal activities of [Cd (L) X2] complexes with a new schiff base ligand. Serb Chem Soc 2014;79:793-804.

9. Herdwiani W, Soemardji AA, Elfahmi I, Tan MI. A review of cinnamon as a potent anticancer drug. Asian J Pharm Clin Res 2016;9:8-13.

10. Patil NR, Gadagil S. Performance of chrom agar medium and conventional methods for detection of methicillin-resistant Staphylococcus aureus. Asian J Pharm Clin Res 2016;9:136-9.

11. Parekh BB, Vyas PM, Sonal R Vasant, Joshi MJ. Thermal, FT-IR and dielectric studies of gel grown sodium oxalate single crystals. Bull Mater Sci 2008;31:143-7.

12. Shedam MR, Venkateswara Rao A. Effect of temperature on the nucleation and growth of cadmium oxalate single crystals in silica gels. Mater Chem Phys 1998;52:263-6.

13. Anandha Babu G, Sreedhar S, Venugopal Rao S, Ramasamy P. Synthesis, growth, structural, thermal, linear and nonlinear optical properties of a new organic crystal: dimethyl ammonium picrate. J Cryst Growth 2010;312:1957-62.

14. Rui-Qin Zhong, Ru-Qiang Zou, Daya S Pandey, Tetsu Kiyobayashi, Qiang Xu. A novel 3D micro porous metal-organic framework of cadmium (II) oxalate with diamondoidnetwork. Inorg Chem Commn 2008;11:951-3.

15. Dwi Utami, Ilma Nugrahani, Slamet Ibrahim. Mefenamic acidnicotinamide co-crystal synthesized by using melt crystallization method and its solubility study. Asian J Pharm Clin Res 2017;10:135-9.
16. Bhattacharjee R, Jain YS, Raghybanshi G, Bist Laser HD. Raman and infrared spectra of rochelle salt crystals. J Raman Spectrosc 1988;19:51-8.

17. Brown less NJ, Edwards DA, Mohan MF. Some complexes derived from zinc salicylate or 3, 5-di-tert-butylsalicylate. the crystal structure of (2, 2'-bipyridyl) (methanol) (o-salicylato) (o, o'-salicylato) zinc. Inorg Chim Acta 1999;287:89-94.

18. Kokkonen P, Lajunen LHJ, Jaakkola A, Ruotssalainen $\mathrm{H}$. Kinetic and mechanistic studies on the decomposition of some hydrous iron (II) salicylate complexes. Thermochim Acta 1984;79:289-98.

19. Dhanaraj PV, Rajesh NP, Vinitha G, Bhagavannarayana G. Crystal structure and characterization of a novel organic optical crystal: 2-aminopyridinium trichloroacetate. Mater Res Bull 2011;46:726-31.

20. Mahmood A, Abdulqader M, Saffa Raheem Mahmood, Mohammed MosaJafaar, Anaam Mahmood Abid. Studying of transition metal complexes containing oxalate ion with antibacterial activity. Int J Sci Eng Res 2015;6:855-67.

21. Abou-Hussein AA, Nelly HM, Linert W. Synthesis, solvatochromism, and antimicrobial activities of new binuclear copper (II) mixed-ligand complexes in a ternary system with $\beta$ diketones and diamine ligands. J Coord Chem 2011;64:2592605.

22. Abu-Hussein AA, Linert W. Redox, thermodynamic and spectroscopic of some transition metal complexes containing heterocyclic Schiff base ligands. Spectrochim Acta Part A 2009;74:214-23.

23. Tweedy BG. Plant extracts with metal ions as potential antimicrobial agents. Phytopatology 1964;55:910-8.

24. Jeyaprakash Dharma-Raja, Paramasivam Subarea, Thirugnanasam, Esakkidurai, Sutha Shobana. Coordination behavioral and bio-potent aspects of $\mathrm{Ni}$ (II) with 2aminobenzamide and some amino acid mixed ligands-part II: synthesis, spectral, morphological, and pharmacological and DNA interaction studies. Spectrochimica Acta Part A 2014;132:604-14.

25. Singh Jadon SC, Gupta N, Singh RV. Synthetic and biochemical studies of some hydrazine carbodithioic acid derivatives of dioxomolybdenum (VI). Indian J Chem 1995;34A:733-6.

26. Zahid H, Chohan M. Ni (II), Cu (II) And Zn (II) metal chelates with some thiazole derived Schiff-bases. Their synthesis, characterization and bactericidal properties. J Metal-Based Drugs 1999;6:75-80.

27. Suresh Kumar S, Athimoolam S, Sridhar B. Hydrogen bonding motifs, spectral characterization, theoretical computations and anticancer studies on chloride salt of 6-mercaptopurine: an assembly of corrugated lamina shows enhanced solubility. J Mol Struct 2015;1098:332-41.

28. Tamara Todorovic, Alessia Bacchi, Nenad Juranic, Katarina Andelkovic. Synthesis and characterization of novel Cd (II), Zn (II) and $\mathrm{Ni}$ (II) complexes with 2-quinolinecarboxaldehyde selenos emicarbazone. Crystal structure of bis (2quinolinecarboxaldehyde seleno semicarbazonato) nickel (II). Polyhedron 2007;26:3428-36.

29. Jeena K, Liju VB, Kuttan R. Antitumor and cytotoxic activity of ginger essential oil (Zingiber officinale roscoe). Int J Pharm Pharm Sci 2015;7:341-4.

30. Vinod Singh, Pooja Singh, Ashish K Singh. Synthesis, structural and corrosion inhibition studies on cobalt (II), nickel (II), copper (II) and zinc (II) complexes with 2-acetylthiophene benzoyl hydrazine. Inorg Chim Acta 2011;379:56-63.

31. Kiran Singh, Manjeet Singh Barwa, Parikshit Tyagi. Synthesis and characterization of cobalt (II), nickel (II), copper (II) and zinc (II) complexes with Schiff base derived from 4-amino-3mercapto-6-methyl-5-oxo-1, 2, 4-triazine. Eur J Med Chem 2007;42:394-402. 